\title{
The Validity and Reliability of Teacher Efficacy Revisited in Malaysia Secondary Schools
}

\author{
Teh Pei Ling, Zaidatol Akmaliah Lope Pihie, Soaib Asimirin, \& Foo Say Fooi \\ University Putra Malaysia, Selangor, Malaysia
}

Received: Dec. 17, 2014 Accepted: Jan. 19, 2014 Published: February 1, 2015

doi:10.5296/jse.v5i1.6802 URL: http://dx.doi.org/10.5296/jse.v5i1.6802

\begin{abstract}
In the education arena, teachers are the front line education workforce who educate the young people and bring positive impact to the new generation in a country. The roles of the teacher are pertinent in ensuring the success of students in pursuing their tertiary level from their common primary and secondary school education. With a high teacher efficacy level, a teacher is committed to teach more effectively and efficiently (Coladarci, 2010). Teacher's efficacy research has been widely conducted in various international education settings but it is still important to revisit the validity and reliability of teacher efficacy in Malaysia context. Confirmatory factor analysis (CFA) was used to assess the uni-dimensionality, validity, reliability and fitness of teacher efficacy model. The teacher efficacy items have Cronbach's alpha value greater than 0.70 for the reliability of three sub-constructs. The convergent and discriminant validity were also established as they fulfilled the criteria. Lastly, the teacher efficacy measurement model fulfilled the criteria for the goodness-of-fit in SEM and it is fit to embark to the structural modelling in SEM.
\end{abstract}

Keywords: Teacher Efficacy, Validity, Reliability, SEM, Malaysia 


\section{Introduction}

In Malaysia, all government teachers are well-trained in any government teaching college and a certificate of fit to teach will be granted to the pre-service teachers (Ministry of Education, 2011). A professionally trained teacher has self-efficacy that will help boast the effectiveness in teaching (Coladarci, 2010). Teacher's efficacy is partly encountered for teacher's action in teaching and thus leads to students' performance (Protheroe, 2008). Many researches were conducted on teacher efficacy in different education settings: in local and international, however, there is still a need to revisit the reliability and validity of the instruments subject to Malaysia setting.

The purpose of this study is to examine the validity and reliability of teacher's self-efficacy scales (TSES) by Tschannen-moran \& William, (2001); Tschannen-Moran, Hoy, \& Hoy, (1998) in the Malaysian secondary school teachers. Confirmatory factor analysis (CFA) method was used to analyse the following research question:

Research Question:

Is there any relationship between the teacher efficacy model and the three sub-constructs, namely (i) efficacy in student engagement, (ii) efficacy in Instructional strategies and (iii) efficacy in classroom management?

\section{Literature Review}

According to Bandura (1997), one important construct, perceived self-efficacy, mediates learning and behavior. Self-efficacy is a future-oriented belief about the competence a person expects to display in a given situation (Bandura, 2001). He also (1986) noted, evidence suggests that people who see themselves as efficacious set themselves challenges that enlist their interest and involvement in activities. This means a more efficacious teacher is willing to take risks and to experiment more effective ways in their teaching. More trails and errors in the teaching strategies would be explored for the benefits of the students whom they teach. Research on the effects of teachers' sense of self-efficacy has confirmed these results by showing teachers' efficacy beliefs are related to their professional learning and to their enhancement of student achievement (Bandura, 1993; Goddard, Hoy, \& Hoy, 2000). Furthermore, Bandura (1986) argued that individuals are more likely to develop a positive sense of self-efficacy in settings where there are challenging and attainable goals with specific standards. To promote self-efficacy, goals must be valid and clear and to include short-term objectives that are easy to be understood within the context of achieving longer-term goals. In an educational context, teaching efficacy has been shown to affect one's sense of self- worth, motivation, attitude, capabilities, and commitment.

\subsection{Efficacy in student engagement (SE)}

Engagement refers to the intensity and emotional quality of students' involvement in initiating and carrying out learning activities (Bandura, 2006). It comprises both behavioural and emotional components. Students who can engage themselves in learning show sustained behavioral involvement in learning activities along with positive emotion. They probably 
show positive emotions such as enthusiasm, optimism, curiosity and learning interest during the classroom interaction. When they are more engaged, they are active learners. Previous research has shown that students who are engaged in their studies will earn better grades, score higher on achievement test and show better personal adjustment to the schools (Leithwood \& Jantzi, 2010).

\subsection{Efficacy in Instructional Strategies (IS)}

Efficacy in Instructional strategies refers to how far a teacher can create a supportive and conducive learning environment in a class. A teacher with a higher efficacy is more creative and innovative in instructional strategies. Efficacy in instructional strategies measures the strength of teachers' beliefs regarding their ability to implement alternative teaching strategies and to use a variety of assessment strategies in the classroom (Tschannen-Moran et al., 1998). It also measures the level of confidence the secondary school teachers in respond to difficult questions posed by the students and providing appropriate challenge to more capable students.

\subsection{Efficacy in classroom management (CM)}

Efficacy in classroom management measures the strength of teachers' belief regarding the ability to establish a good classroom management system, control some attitude problem students, and get the students to follow classroom rules and regulations. It also measures teachers' confidence in responding to attention seeker students and how to keep them from disturbing the entire teaching and learning in class. Classroom management and class control are two important aspects to be considered in providing a more conducive learning climate. The extent to which teacher believes one is in control of the classroom behavior can be explained by teacher's efficacy (Bandura, 2001). The strength of teachers' convictions in their own effectiveness is likely to affect their behavoiur in a given situation (Bandura, 1986, 2006).

Teacher efficacy in this paper has three dimensions and it is interesting to see how many items are left after CFA then it was used to measure teacher efficacy in Malaysia. This is different from the research done by Murphy, (2013), Ryan \& Harry, (2007) and Horn-turpin, (2009) in terms of instrumentation.

\section{Research Methodology}

The study aimed to examine the validity and reliability of the instrument. The target population of this study was teachers teaching in Malaysia secondary schools. The study was conducted based on individual's efficacy. Only academic teachers' perceptions were used in the data analysis. A proportionate stratified random sampling was used for sampling selection in order to represent a subset of the Malaysian teachers' population and demography in the states of central region in Malaysia. A list of government secondary schools in central region was obtained by the Ministry as it was suitably used to obtain samples from a big and scattered population (Ary, Jacobs, \& Sorensen, 2006). Besides, it also ensured an availability of special characteristics which were needed to run statistical analysis in a study (Neuman, 2006). Although only 379 sample size was needed, 400 questionnaires were distributed to 
teachers. In the end, 385 questionnaires were returned but only 349 were valid for data analysis, yielding a respond rate of about 87.25 percent.

The data were analysed based on Structural Equation Modelling (SEM) using AMOS software (version 20). For this teacher efficacy study, the questionnaire consisted 24 items in three sub-constructs, but after the CFA analysis was conducted, 13 items in the instrument were remained. 5-point Likert scale was used and they were; 5 indicates 'strongly agree', 4 indicates 'agree', 3 indicates 'moderately agree', 2 indicates 'disagree', and 1 indicates 'strongly disagree'. The questionnaire items were adopted from TSES. The original questionnaires were in English language. After validation of questionnaires by the expert panel, it was translated to Malay language to ease understanding of the participants. This is because Malay language is the national language in Malaysia. All Malaysians study and learn this language in a formal setting. The, back-to-back translation was conducted prior the distribution of the questionnaires in schools. The overall model fit is assessed using both absolute fit indices and incremental fit indices. These absolute fit indices include the normed chi square (NC), goodness-of-fit (GFI) index, adjusted goodness-of-fit (AGFI) index, and root mean square error of approximation (RMSEA). The measurement of incremental fit indices comprises the normed fit index (NFI), comparative fit index (CFI), and the Turker Lewis index (TLI) (Byrne, B, 2010; Hair, Black, Babin, \& Anderson, 2010; Hooper, Coughlan, \& Mullen, 2008).

\section{Findings \& Discussion}

The CFA model of teacher efficacy structure hypothesised a priori that: responses to teacher efficacy can be explained by three dimensions; each items has a non-zero loading on teacher efficacy factor that it was designed to measure and has zero loadings on all the other factors; the three dimensions are correlated; and the error terms associated with the item measurements are uncorrelated. A schematic representation of this theoretical construct is reflected in the pathway diagram as shown in Figure 1 below.

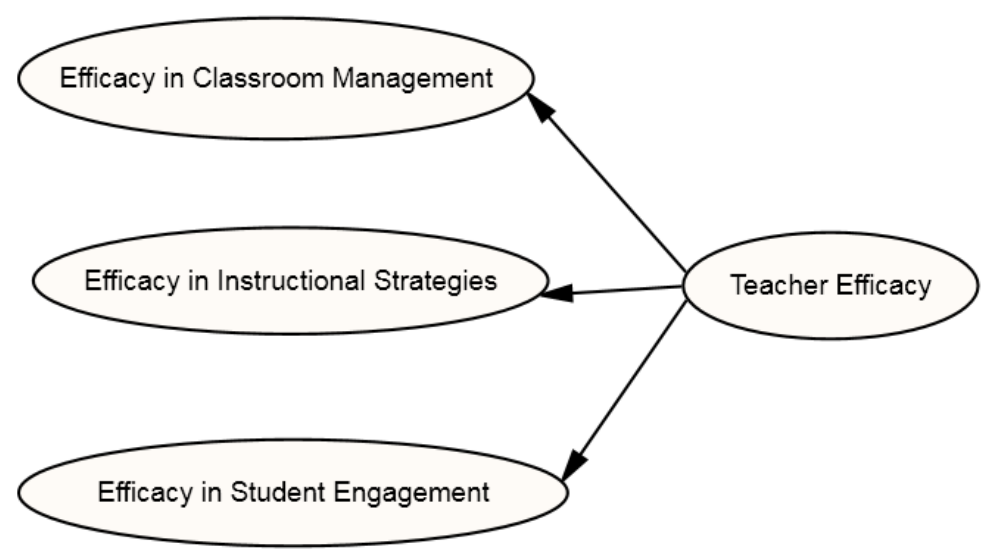

Figure 1. Teacher efficacy with three dimensions 
Confirmatory factor analysis (CFA) using SEM technique is to measure the hypothesized model and revised model on teacher efficacy item. Initially, after a few subsequent revisions, the model has a good fitness of indices. A total of 24 items were measured for validity and reliability of teacher efficacy.

Table 1. Factor loading of items for the sub-domains of Teacher Efficacy

\begin{tabular}{|c|c|c|c|c|c|c|c|}
\hline Sub-domain & & Items & $\begin{array}{l}\text { Factor } \\
\text { Loading } \\
\text { Model } 1 \\
\end{array}$ & $\begin{array}{l}\text { Factor } \\
\text { Loading } \\
\text { Model } 2 \\
\end{array}$ & $\begin{array}{l}\text { Factor } \\
\text { Loading } \\
\text { Model } 3 \\
\end{array}$ & $\begin{array}{l}\text { Factor } \\
\text { Loading } \\
\text { Model } 4 \\
\end{array}$ & Remarks \\
\hline Efficacy & in & & & & & & \\
\hline \multirow{8}{*}{$\begin{array}{l}\text { Classroom } \\
\text { management }\end{array}$} & & TE3 & .71 & .70 & .70 & .70 & \\
\hline & & TE5 & .49 & & & & Deleted \\
\hline & & TE8 & .53 & .52 & & & Deleted \\
\hline & & TE13 & .66 & .66 & .66 & .66 & \\
\hline & & TE15 & .72 & .72 & .73 & .73 & \\
\hline & & TE16 & .62 & .62 & .61 & & $\begin{array}{l}\text { The AVE was not } \\
\text { achieved, so decide to } \\
\text { delete the lowest factor } \\
\text { loading, } .61\end{array}$ \\
\hline & & TE19 & .74 & .74 & .75 & .76 & \\
\hline & & TE21 & .75 & .75 & .75 & .74 & \\
\hline \multirow{8}{*}{$\begin{array}{l}\text { Efficacy } \\
\text { Instructional } \\
\text { Strategies }\end{array}$} & in & TE7 & .56 & .56 & & & $\begin{array}{l}\text { MI has two occurrence, } \\
\text { deleted TE7 }\end{array}$ \\
\hline & & TE10 & .62 & .65 & .64 & & Deleted \\
\hline & & TE11 & .67 & .7 & .69 & .65 & \\
\hline & & TE17 & .69 & .69 & .70 & .70 & \\
\hline & & TE18 & .65 & .66 & .69 & .73 & \\
\hline & & TE20 & .60 & .59 & .57 & & Low factor loading \\
\hline & & TE23 & .71 & .66 & .67 & .68 & \\
\hline & & TE24 & .64 & & & & $\begin{array}{l}\text { It has three times MI } \\
\text { occurrence. Decision to } \\
\text { delete TE24. }\end{array}$ \\
\hline \multirow[t]{8}{*}{$\begin{array}{l}\text { Efficacy } \\
\text { Student } \\
\text { Engagement }\end{array}$} & in & TE1 & .62 & .61 & & & $\begin{array}{l}\text { MI occurs three times, } \\
\text { need to delete TE1. }\end{array}$ \\
\hline & & TE2 & .63 & .62 & .61 & .61 & \\
\hline & & TE4 & .74 & .74 & .71 & .69 & \\
\hline & & TE6 & .71 & .71 & .74 & .75 & \\
\hline & & TE9 & .63 & .64 & .66 & .68 & \\
\hline & & TE12 & .57 & .57 & .56 & & \\
\hline & & TE14 & .61 & .61 & .62 & & \\
\hline & & TE22 & .37 & & & & $<.5$, deleted \\
\hline
\end{tabular}




\section{Mll Macrothink}

The above table shows the uni-dimensionality was achieved, with the loading factor of more than 0.50 (Byrne, B, 2010; Hair et al., 2010). The lowest loading items were removed one at a time. The items were deleted till the optimal results were obtained. Efficacy in Classroom Management, Efficacy in Instructional Strategies and Efficacy in student engagement left with 5 items, 4 items and 4 items respectively.

Table 2. Reliabilities \& Validity Analyses

\begin{tabular}{lllll}
\hline & Items & Reliability & AVE & Construct Reliability \\
\hline Efficacy in Classroom Management & 5 & 0.841 & 0.517 & 0.842 \\
& & & & \\
Efficacy in Instructional Strategies & 4 & 0.780 & 0.477 & 0.785 \\
Efficacy in student engagement & 4 & 0.779 & 0.468 & 0.778 \\
\hline
\end{tabular}

The reliability analysis is assessed using the Cronbach's alpha coefficient and composite reliability. As shown in Table 2, the Cronbach's Alpha values for all constructs are above 0.70 , meeting the desirable value suggested by Pallant (2010). Likewise, the values of composite reliability for all constructs are greater than the cut-off criterion of 0.60 proposed by Bagozzi et al., (1991).

As for the validity of measurement instrument, both convergent validity, and discriminant validity are tested. Convergent validity can be checked through the estimation of average variance extracted. Referring to Table 2, the values of average variance extracted for all constructs are very close to or greater than 0.50 recommended by Fornell (1981). As a result, convergent validity is established.

Table 3. Discriminant validity of the constructs

\begin{tabular}{llll}
\hline Construct & (1) & (2) & (3) \\
\hline (1) Efficacy in student engagement & $\mathbf{0 . 7 1 9}$ & & \\
(2) Efficacy in Instructional strategies & 0.701 & $\mathbf{0 . 6 9 1}$ & \\
(3) Efficacy in classroom management. & 0.722 & 0.64 & $\mathbf{0 . 6 8 4}$ \\
\hline
\end{tabular}

Note: Diagonals represent the square root of the average variance extracted, while the other entries represent the squared Correlations Coefficients $\left(r^{2}\right)$.

Table 3 shows that the value of square root of AVE was greater than $r^{2}$ for efficacy in student engagement $0.498(0.500)$, efficacy in instructional strategies and efficacy in classroom management (0.545). This indicated that the teacher efficacy instruments have obtained minimal discriminant validity. 


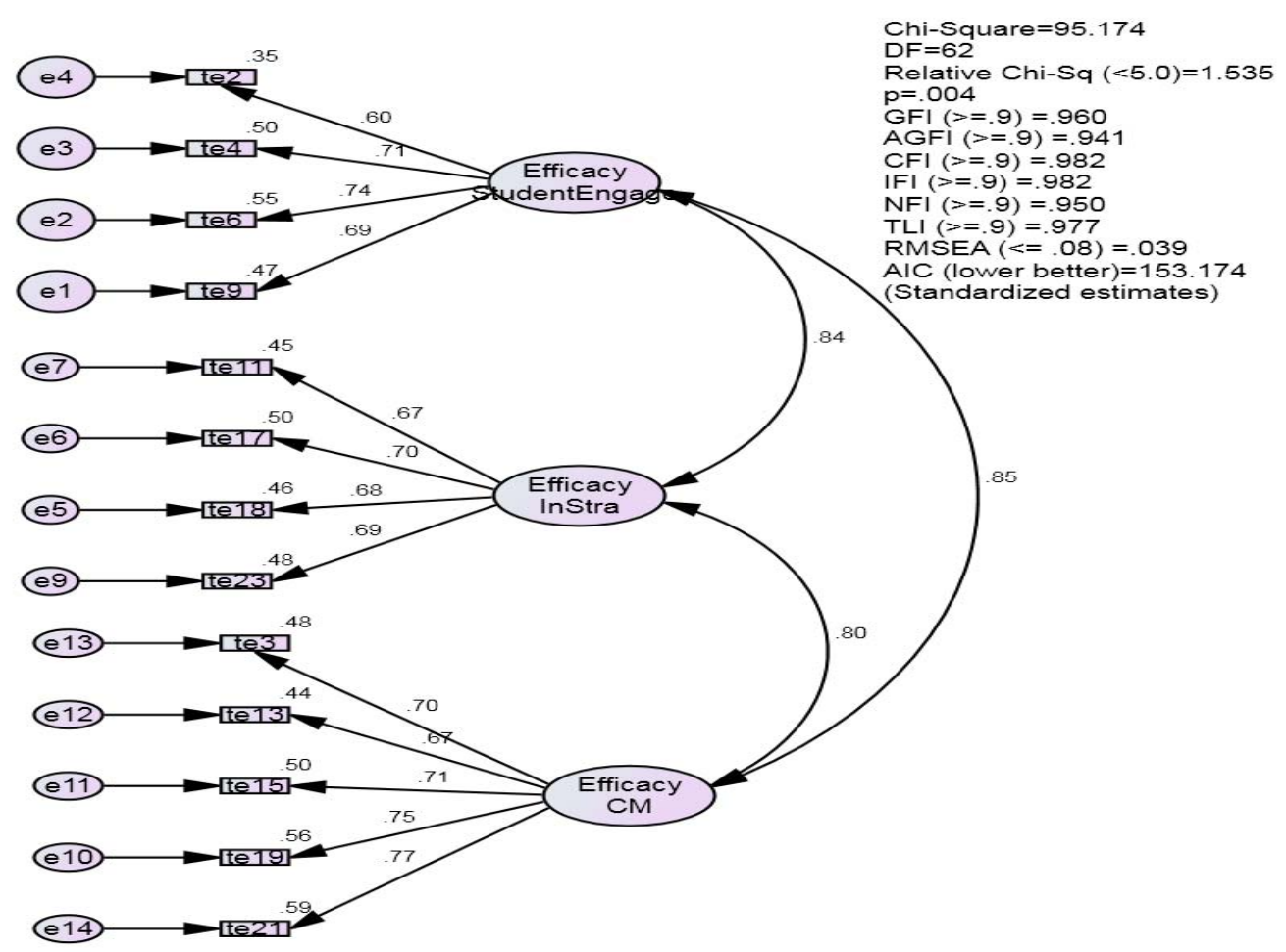

Figure 2. Measurement model for teacher efficacy

Figure 2 shows the results of the three-factor measurement model of teacher efficacy. To check the fitness of the measurement model, the analysis depended on the fitness index and literature support that were referred to (Hair et al., 2010). The fit indices were examined and acceptable by the recommended values with GFI (0.960), CFI (0.982), NFI (0.950), TLI (0.977) were more than 0.90, and RMSEA (0.039) was less than 0.08. The chi-square of goodness-of-fit indexes value obtained was 95.174 . It shows the revised measurement model is fit to be used for analysis for the next structural model.

The findings confirm that the teacher efficacy, with three sub-scales is uni-dimensional. Factor analysis showed that the 13 items were loaded into three dimensions of teacher efficacy after forced extraction. All the items were very well fitted (more than 0.50) (Byrne, B, 2010).

Then, convergent validity has established for the three sub-constructs, but AVE value for efficacy in instructional strategies (0.477) and efficacy in student engagement (0.468) was near to 0.50 compared to Efficacy in classroom management, 0.517 (higher than 0.50 ), and CR value for each sub-construct was more than 0.70, as all the evidences supported and met the level recommended by (Hair et al., 2010). Furthermore, the AVE for discriminant validity exceeded $\mathrm{r}^{2}$ and met the criteria set as recommended by (Fornell, 1981). 


\section{Conclusion}

The CFA was used to test the construct validity of teacher efficacy items. The aim of this test was to determine the convergent validity, and it was found that the factor loading value was greater than 0.5, AVE was greater than 0.50 and CR was greater than 0.70. Meanwhile, the testing for discriminant validity also found that the AVE was greater than $\mathrm{r}^{2}$ (square of correlation between two factors) and fulfilled all the proposed conditions. The analysis using CFA for teacher efficacy items fit to the data based on the fit index. This suggested that the teacher efficacy was represented by the three sub-constructs. A total of 13 items showed optimal convergent validity and discriminant validity. Teacher efficacy (TSES) instrument was adopted and ready to embark in structural modelling in SEM AMOS. Teacher's efficacy among secondary school teachers in Malaysia has different adaptation of the items after CFA deletion as compared to research in Western Countries (Lewandowski, 2005; Murphy, 2013; Ryan \& Harry, 2007).

\section{References}

Ary, D., Jacobs, L. C., \& Sorensen, C. (2006). Introduction to Research in Education (8th ed.). Belmont: Wadsworth Cengage Learning.

Bagozzi, R. P., Yi, Y., \& Singh, S. (1991). On the use of structural equation models in experimental designs: Two extensions. International Journal of Research in Marketing, 8(2), 125-140. http://dx.doi.org/10.1016/0167-8116(91)90020-8

Bandura, A. (1986). Social foundations of thought and action. New Jersey: Prentice-Hall.

Bandura, A. (2001). SOCIAL COGNITIVE THEORY: An Agentic Perspective. Annual Review of Psychology, 52, 1-26.

Bandura, A. (2006). Guide for constructing self-efficacy scales. In Self-Efficacy Beliefs of adolescents (pp. 307-337). http://dx.doi.org/10.1146/annurev.psych.52.1.1

Byrne, B, M. (2010). Structural Equation Modeling with AMOS:: Basic Concepts, Applications and Programming (Second edi., p. 396). New York: Routledge.

Coladarci, T. (2010). Teachers ' Sense of Efficacy and Commitment to Teaching. The Journal of Experimental Education, 60(4), 323-337. http://dx.doi.org/10.1080/00220973.1992.9943869

Fornell, C. and D. . L. (1981). Evaluating Structural Equation Models with Unobservable Variables and Measurement Error. Journal of Marketing Research, 18(1), 41-54. http://dx.doi.org/10.2307/3151312

Hair, J. F., Black, W. C., Babin, B. J., \& Anderson, R. E. (2010). Multivariate Data Analysis: A Global Perspective (Seventh Ed., p. 800). New Jersey: Pearson Education.

Hooper, D., Coughlan, J., \& Mullen, M. R. (2008). Structural Equation Modelling: Guidelines for Determining Model Fit, 6(1), 53-60. 
Horn-turpin, F. D. (2009). A study examining the effects of transformational leadership behaviours on the factors of teaching efficacy, job satisfaction and organisational commitment as perceived by special education teachers. Thesis by Virgina Polytechnic Institute and State University.

Lewandowski, K. H. L. (2005). A study of the relationship of teachers' self-efficacy and the impact of leadership and professional development. Indiana University of Pennsylvania.

Ministry of Education. (2011). Pelan strategik interim 2011-2020. Ministry of Education. Retrieved from www.moe.gov.my/bppdp

Murphy, D. (2013). An examination into the relationship between teacher efficacy and organizational commitment of special education teachers. Thesis by Northeasten University.

Neuman, W. L. (2006). Social Research Methods (6th ed.). Boston: Pearson Education.

Pallant, J. (2010). SPSS: Survival Manual (4th ed.). Berkhire: Open University Press.

Protheroe, N. (2008). What Is It and Does It Matter? Teacher Efficacy: (p. 4).

Ryan, H. D., \& Harry, D. (2007). An examination of the relationship between teacher efficacy and teachers' perceptions of their principals' leadership bahaviors. University of North Texas.

Tschannen-moran, D. M., \& William, C. (2001). Directions for Scoring the Teachers' Sense of Efficacy Scale 1, 90.

Tschannen-Moran, M., Hoy, a. W., \& Hoy, W. K. (1998). Teacher Efficacy: Its Meaning and Measure. Review of Educational Research, 68(2), 202-248. http://dx.doi.org/10.3102/00346543068002202 